\title{
Rapid on-site evaluation of cytology for EUS- and EBUS-guided fine-needle aspiration
}

\author{
Kartik Ramakrishna ${ }^{1}$
}

Received: 18 February 2017 / Accepted: 24 February 2017 /Published online: 14 March 2017

(C) Indian Society of Gastroenterology 2017

Upper gastrointestinal endoscopic ultrasound (EUS)- and endobronchial ultrasound (EBUS)-guided fine-needle aspiration cytology (FNAC) are being increasingly used as a safe and non-surgical method to sample tissue from mediastinal, para-aortic, and perihilar masses and lymph nodes. EUS- and EBUS-guided FNAC have greatly enhanced our diagnostic armamentarium in pulmonary medicine and gastroenterology. The diagnosis of tuberculosis is confirmed by the finding of granulomatous inflammation and the isolation of Mycobacterium tuberculosis in culture by FNAC of mediastinal or retroperitoneal nodes. The diagnosis and staging of malignancy are also aided by these techniques.

Adequacy of tissue sampling is vital to the diagnostic yield of these procedures and has become even more crucial in an era of increasing molecular testing for genotype-targeted therapies such as evaluation of epidermal growth factor receptor (EGFR) mutations in non-small cell lung cancer. A number of factors are thought to be associated with yield from these procedures, such as high-volume centers, lesion site, lymph node size, positive PET scans, biopsy of more than two sites, needle size, number of passes, and expertise of the scopist [1-6].

On-site preparation and evaluation of smears by a cytopathologist during the procedure (rapid on-site evaluation [ROSE]) ensures that smears are adequately cellular and are likely to yield a diagnosis. Several studies have demonstrated that the diagnosis at on-site evaluation correlates well with the final cytopathological diagnosis. Multiple studies have shown that ROSE increases diagnostic yield by about $10 \%$ to $15 \%$ [7,

Kartik Ramakrishna

kartik_ramakrishna@hotmail.com

1 Division of Pulmonary and Critical Care Medicine, Geisinger Medical Center, Danville, PA, USA
8]. ROSE has also been shown to reduce the number of needle passes performed [9]. Due to proximity to vital structures, risk of complications such as bleeding, and time, fewer needle passes may be beneficial. These benefits may be more pronounced in centers with trainees. This has led to the establishment of ROSE as the default practice in many institutions where EUS-FNA or EBUS-FNA is offered. A survey of endosonologists indicated that ROSE was used more often by US (98\%) than by European $(48 \%)$ or Asian $(55 \%)$ respondents [10].

However, it is not clear whether ROSE will differentially impact diagnostic yield in pancreatic vs. lymph nodal disease. A meta-analysis of seven studies (one randomized) with a total of 1299 patients, comparing EUS-FNAC with and without ROSE, concluded that ROSE did not make a significant difference to cytological adequacy or diagnostic yield [11]. Although overall the number of needle passes was similar in the two groups, in the one study which was randomized, seven passes were made for cytology in the absence of ROSE compared to four passes in the presence of ROSE [12].

ROSE requires the availability of a trained cytopathologist on site at the time of the endoscopic procedure. On-site services may not necessarily be available in hospitals in developing countries, particularly those in the public sector. Furthermore, ROSE is associated with higher costs [12]. In this issue of the Journal, Sharma et al. describe their experience of EUS-FNAC without ROSE and indicate that the adequacy of the samples for diagnosis was very good, ranging from $73 \%$ for lymph nodes to $100 \%$ for mediastinal, renal, and suprarenal masses [13].

A number of parameters may be used to judge the effectiveness of EUS-FNAC. These include cytological adequacy, diagnostic yield, number of passes required for diagnosis, and diagnostic characteristics (number of true-positive, true-negative, false-positive, and false-negative observations). 
Several of these parameters are missing in the study by Sharma et al. which has mainly described diagnostic adequacy and number of passes made. Of interest, the median number of passes was two, which is lower than would be practiced in most centers.

ROSE performed by endosonographers trained in cytological interpretation was found to significantly increase diagnostic accuracy in one study [14] and found to be on par with evaluation by a cytopathologist in another study [15].

EUS- and EBUS-guided FNA have high a diagnostic yield, especially in high-volume centers, and with experienced endosonographers. We however owe it to our patients to strive for perfection. ROSE is a step in this direction and hence should be performed where available and feasible, while perhaps in other centers, evaluation of smears by the endosonographer may be a viable substitute.

\section{References}

1. Ost DE, Ernst A, Lei X, et al. Diagnostic yield of endobronchial ultrasound-guided transbronchial needle aspiration: results of the AQuIRE Bronchoscopy Registry. Chest. 2011;140:1557-66.

2. Song TJ, Kim JH, Lee SS, et al. The prospective randomized, controlled trial of endoscopic ultrasound-guided fine-needle aspiration using $22 \mathrm{G}$ and $19 \mathrm{G}$ aspiration needles for solid pancreatic or peripancreatic masses. Am J Gastroenterol. 2010;105:1739-45.

3. Madhoun M, Wani SB, Early DS, et al. The diagnostic accuracy of 22- and 25-gauge needles in EUS-FNA of solid pancreatic lesions: a meta-analysis. Gastrointest Endosc. 2011;73:AB154.

4. Imazu H, Uchiyama Y, Kakutani H, et al. A prospective comparison of EUS-guided FNA using 25-gauge and 22-gauge needles. Gastroenterol Res Pract. 2009;2009:546390.

5. Xu MM, Jia HY, Yan LL, Li SS, Zheng Y. Comparison of two different size needles in endoscopic ultrasound-guided fine-needle aspiration for diagnosing solid pancreatic lesions: a meta-analysis of prospective controlled trials. Medicine (Baltimore). 2017;96: e5802.

6. LeBlanc JK, Ciaccia D, Al-Assi MT, et al. Optimal number of EUSguided fine needle passes needed to obtain a correct diagnosis. Gastrointest Endosc. 2004;59:475-81.

7. Iglesias-Garcia J, Lariño-Noia J, Abdulkader I, Domínguez-Muñoz JE. Rapid on-site evaluation of endoscopic-ultrasound-guided fineneedle aspiration diagnosis of pancreatic masses. World $\mathrm{J}$ Gastroenterol. 2014;20:9451-7.

8. Alper E, Onur I, Arabul M, et al. Endoscopic ultrasound-guided tissue sampling: how can we improve the results? Turk J Gastroenterol. 2016;27:1-3.

9. Schmidt RL, Walker BS, Howard K, Layfield LJ, Adler DG. Rapid on-site evaluation reduces needle passes in endoscopic ultrasound-guided fine-needle aspiration for solid pancreatic lesions: a risk-benefit analysis. Dig Dis Sci. 2013;58:3280-6.

10. van Riet PA, Cahen DL, Poley JW, Bruno MJ. Mapping international practice patterns in EUS-guided tissue sampling: outcome of a global survey. Endosc Int Open. 2016;4:E360-70.

11. Kong F, Zhu J, Kong X, et al. Rapid on-site evaluation does not improve endoscopic ultrasound-guided fine needle aspiration adequacy in pancreatic masses: a meta-analysis and systematic review. PLoS One. 2016;11:e0163056.

12. Lee LS, Nieto J, Watson RR, et al. Randomized noninferiority trial comparing diagnostic yield of cytopathologist-guided versus 7 passes for EUS-FNA of pancreatic masses. Dig Endosc. 2015; doi:10.1111/den.12594.

13. Sharma SS, Jain M, Maharshi S. High diagnostic yield of endoscopic ultrasound guided fine needle aspiration without onsite cytopathologist. Indian J Gastroenterol. 2017; 36: doi 10.1007/ s12664-017-0730-z.

14. Hayashi T, Ishiwatari $\mathrm{H}$, Yoshida M, et al. Rapid on-site evaluation by endosonographer during endoscopic ultrasound-guided fine needle aspiration for pancreatic solid masses. J Gastroenterol Hepatol. 2013;28:656-63.

15. Hikichi T, Irisawa A, Bhutani MS, et al. Endoscopic ultrasoundguided fine-needle aspiration of solid pancreatic masses with rapid on-site cytological evaluation by endosonographers without attendance of cytopathologists. J Gastroenterol. 2009;44:322-8. 